\title{
Nebulisers for chronic obstructive pulmonary disease
}

\author{
B R O’Driscoll
}

Definition of chronic obstructive pulmonary disease

In this paper the term "chronic obstructive pulmonary disease" (COPD) is used as defined in the forthcoming British Thoracic Society guidelines for the management of COPD (1997) as a chronic slowly progressive disorder characterised by airways obstruction (reduced forced expiratory volume in one second $\left(\mathrm{FEV}_{1}\right)$ and ratio of $\mathrm{FEV}_{1}$ to forced vital capacity (FVC)) which does not change markedly over several months. Most of the lung function impairment is fixed, althugh some reversibility can be produced by bronchodilator (or other) therapy.

The guidelines indicate that, in practice, a diagnosis of COPD requires a history of chronic progressive symptoms such as cough, wheeze and/or breathlessness without intervening periods of "wellness", usually a cigarette smoking history of more than 20 pack years, and objective evidence of airways obstruction (ideally verific ric testing) that does not return entirely to normal with treatment.

\section{Acute exacerbations of COPD}

Current clinical practice is based largely on tradition rather than on careful clinical trials Although patients with COPD are considered to have relatively static lung function, most have some reversibility and peak flow will often show a modest rise during the first few days in hospital. For rexple, Rebuck et al found that in 51 patients with COPD, the mean peak flow in 51 patients with COPD, the mean peak flow
increased from $701 / \mathrm{min}$ to $951 / \mathrm{min}$ (36\% rise) increased from $701 / \mathrm{min}$ to $95 \mathrm{l} / \mathrm{min}$ ( $36 \%$ rise) bronchodilator, ${ }^{1}$ and a later study reported a rise of $19 \%$ in mean peak flow from $1131 / \mathrm{min}$ to $134 \mathrm{l} / \mathrm{min}$ in 47 patients with COPD after nebulised bronchodilator treatment. ${ }^{2}$ These studies demonstrate that patients with acute exacerbations of COPD can respond to high doses of bronchodilator drugs.

Several studies have suggested that patients with acute asthma or COPD may respond better to treatment with a $\beta$ agonist given by nebuliser than by metered dose inhaler. ${ }^{3-5}$ However, other authors have suggested that treatment with a metered dose inhaler (given ment with a mered dose inhaler (given through a spacer device) may be as effective as
nebulised treatment in the acute situation. ${ }^{6-8}$ It nebulised treatment in the acute situation..$^{6-8}$ It
is difficult to compare these results directly as the patient groups and inhaler devices were different and most studies have contained relatively small numbers of patients, making it difficult to draw definite conclusions about the difference between treatments. However, it is generally agreed that the bronchodilation obtained is largely a reflection of the dose of bronchodilator administered rather than the mode of administration. ${ }^{9}$ It is therefore unlikely that treatment with either a nebuliser or a metered dose inhaler will give superior results given to the lungs by each device. The question therefore becomes one of convenience and cost. For low dose bronchodilator therapy - for example, $100-400 \mu \mathrm{g}$ salbutamol or terbutaline treatment with a metered dose inhaler is more convenient whilst a nebuliser can deliver higher doses more easily. advantage of being independent of effort or breathing pattern when a patient is distressed. This means that a patient can begin nebulised treatment using a mask or a mouthpiece while the medical attendent can continue with other tasks. The use of a metered dose inhaler in this situation would require the medical attendant (or respiratory therapist or nurse) to stand by the patient and supervise or administer multiple doses of treatment, possibly more than 20 , at one minute intervals. Breathless patients are less likely to be able to inspire slowly or breath hold for optimum lung deposition from a metered dose inhaler.

The optimum dose of bronchodilator treatment ( $\beta$ agonist or anticholinergic) in acute COPD is not known. Mestitz et al showed that terbutaline was equally effective given by metered dose inhaler or nebuliser and the dose response was still rising at $40 \mathrm{mg} .{ }^{9}$ However, doses of $\beta$ agonist above $5-10 \mathrm{mg}$ tend to be associated with unacceptable side effects such as tremor or palpitations. Gross and colleagues showed that the optimum response to ipratropium bromide occurred at $0.4-0.6 \mathrm{mg} .{ }^{10} \mathrm{~A}$ review of practice in Britain shows that salbutamol or terbutaline $(5 \mathrm{mg})$, with or without ipratropium bromide $(0.25-0.5 \mathrm{mg})$, is usually administered to patients with acute airflow obstruction ${ }^{11}$ This of salbutamol followed by 25 inhalations of ipratropium bromide via a metered dose inhaler. Most doctors mix salbutamol and ipratropium bromide respirator solutions in a single nebuliser chamber and administer it immediately. ${ }^{11}$ It has recently been suggested that the Turbohaler dry powder device may be used effectively by patients with severe airflow effectively by patients with severe airflow
obstruction. ${ }^{1213}$ This would allow the administration of $5 \mathrm{mg}$ (10 puffs) or $10 \mathrm{mg}$ (20 puffs) of terbutaline almost as conveniently as with a nebuliser.

Nebulised treatment might have a further beneficial effect due to its physical properties. Inhaled droplets may alter mucus viscosity in 
the airways and nebulised terbutaline or saline may help patients with bronchiectasis to expectorate. ${ }^{14}$ Whether this is also true in acute COPD is not known.

Does the addition of an anticholinergic agent to a high dose $\beta$ agonist have any benefit in the treatment of acute exacerbations of COPD? Although combined treatment seems to be more effective in acute asthma, ${ }^{12}$ the same authors found that patients with acute exacerbations of COPD did not seem to gain any extra benefit from combined treatment. Furthermore, a recent study of 70 patients admitted to hospital with acute COPD who were not already taking combination nebuliser treatment at home failed to show that the addition of nebulised anticholinergic treatment during their stay in hospital had a clear beneficial effect on symptoms, spirometric parameters, or length of stay. ${ }^{15}$ These results were unexpected as combination treatment produces increased bronchodilatation in patients with stable bronchitis. ${ }^{1617}$ Furthermore, patients with severe but stable COPD who took part in a home nebuliser trial had slightly (but not significantly) higher mean daily peak flow rates using combined salbutamol and ipratropium bromide than using either agent alone. ${ }^{18}$ The exact role of ipratropium bromide in acute exacerbations of COPD therefore remains incompletely defined and further studies are required.

The optimum duration of nebuliser treatment is not known. Based on clinical practice and experience, it is suggested that nebulised salbutamol $(2.5-5 \mathrm{mg})$ or terbutaline (5$10 \mathrm{mg}$ ) be given 4-6 hourly for 24-48 hours or until the patient is clinically stable. Ipratropium bromide $(0.5 \mathrm{mg})$ should be added if the patient is known to benefit from it or if there is a poor response to $\beta$ agonist therapy. The patient should be changed to a metered dose inhaler 24-48 hours before discharge to ensure that the patient is stable, to check the inhaler technique, and to reassure the patient that his or her condition is controlled by their usual medication.

\section{Home nebuliser use for patients with \\ COPD}

This remains a controversial area and the arguments for and against home nebuliser treatment have been well reviewed. ${ }^{1920}$ Home nebulisers have been widely used in the past for patients who were unable to use metered dose inhalers. With the advent of spacer devices, self activated inhalers, dry powder inhalers, and other inhalation devices this is no longer a valid reason for prescribing a home nebuliser except in a very few cases. ${ }^{1920}$ Home nebuliser except in a very few cases. ${ }^{10}$ Home nebulisers may benefit some patients with
COPD who require large doses of inhaled medication. Most patients derive optimum benefit from standard doses of bronchodilators administered by metered dose inhaler and, for these patients, giving increasing doses of medication produces little subjective or objective benefit. ${ }^{21}$ However, the maximum bronchodilator response to $\beta$ agonists and anticholinergic agents may not occur until very high doses are reached (more than 20 puffs of high doses ar these doses it is more convenient (and less is more convenient (and less expensive) to deliver the medication by small volume nebuliser.

Other patients may benefit from the physical properties of nebulised treatment. Nebulised terbutaline aids sputum clearance in patients with bronchiectasis. ${ }^{14}$ Differing particle size and particle distribution in the airways may produce different responses to treatment with nebulisers and metered dose inhalers in some patients even if the same dose is given. In one study a group of patients with COPD had a higher peak flow and subjective response to nebulised drugs than to the same drugs given by metered dose inhaler and spacer. ${ }^{18}$ However, other patients had a higher subjective and objective response to the lower dose of treatment given by metered dose inhaler and spacer. ${ }^{18}$ These differences may be due to the different distribution of particles in the airways between patients. The dose of inhaled drug available for systemic absorption also differs between a metered dose inhaler and a nebuliser and this could could increase or decrease the systemic effects for the same dose.

EVIDENCE FROM CLINICAL TRIALS OF BRONCHODILATOR TREATMENT IN COPD

Given the differing requirements (and inhaler skills) of different patients, and the variable performance characteristics of different inhaler and nebuliser devices, it is hardly surprising that clinical trials of home nebulisers in COPD have yielded conflicting results. Some studies have shown that nebulisers were superior to metered dose inhalers based on improvements in spirometric values and symptoms. ${ }^{182223} \mathrm{In}$ other studies nebulisers and metered dose inhalers were found to be equally effective. ${ }^{92425}$ Some of the differences in these studies can be explained by differences in patient groups and doses and devices. For example, Jenkins et $a l^{25}$ excluded patients who did not have a satisfactory response to conventional metered dose inhaler treatment, whereas these are presumably the patients who are most likely to benefit from high dose nebuliser treatment. There are also methodological problems with home nebuliser trials as there is no perfect placebo for a nebulised treatment (nebulised saline might alter airway calibre or mucus clearance). Morrison et $a l^{23}$ compared nebulised saline with nebulised ipratropium bromide and fenoterol in a double blind, randomised, placebo controlled study. The mean daily peak plow (PEF) rose by 19\% (from 164 th min) on the active nebuliser treatment compared with nebulised saline supplemented by "rescue" metered dose inhaler bronchodilator therapy. This impressive rise in PEF was almost identical to that observed by O'Driscoll et al. ${ }^{18}$ These studies suggest that there is, indeed, a small population of patients with severe COPD who derive greater subjective and objective 
benefit from a high dose nebulised bronchodilator than from lower dose metered dose inhaler treatment.

\section{PATIENT ASSESSMENT}

Details of home nebuliser assessment for patients with COPD are given in the guidelines on page S10. The key steps are:

1. An assessment by a respiratory specialist to confirm the diagnosis of COPD and to explore other treatment options. An assessment needs to be made also of a patient's ability to use hand held inhalers.

2. A recording of baseline home peak flow taken twice daily on the patient's usual inhaled treatment.

3. A trial of treatment with an oral steroid, if not already done.

4. A trial of high dose treatment by hand held inhaler - for example, a dry powder device or metered dose inhaler and spacer with $1 \mathrm{mg}$ terbutaline or $400 \mu \mathrm{g}$ salbutamol and $160 \mu \mathrm{g}$ ipratropium bromide four times daily.

5. A formal trial of a home nebuliser - for example, $2.5-5 \mathrm{mg}$ salbutamol or $5-10 \mathrm{mg}$ terbutaline four times daily or ipratropium bromide $0.25-0.5 \mathrm{mg}$ four times daily or a combination of these treatments.

6. A careful assessment of the patient's response to these treatments over at least two weeks each. Laboratory based single dose reversibility studies will not identify patients who should be given home nebuliser therapy and such trials cannot identify the best treatment options for individual patients. ${ }^{2627}$

7. After an assessment process the clinician must decide with the patient if the nebulise treatment has produced subjective and objective benefit. The doctor and patient need to discuss whether the degree of benefit is sufficient to justify the high cost and inconvenience of home nebuliser therapy.

SIDE EFFECTS AND OUTCOME

Safety issues are important when patients are given high dose treatment at home. There has been considerable concern about the use of high dose $\beta$ agonists in patients with asthma ${ }^{28}$ and the same concerns (arrhythmias, tachyphylaxis, failure to call help in an emergency) apply to patients with COPD. Patients with severe airflow obstruction taking high doses of treatment are more likely to die of their disease than patients with milder disease taking standthan patients with milder disease taking stand-
ard doses. This is likely to be a marker of ard doses. This is likely to be a marker of disease severity rather than an effect of the drugs themselves. Studies of asthma death have found no evidence for direct toxicity of the bronchodilator drugs. ${ }^{29} 30$

Little is known about the long term prognosis of patients with COPD who use home nebulisers. The drugs might be toxic in high doses, especially in patients with coexistent cardiac disease $^{28}$ due to an intrinsic cardiac effect or to indirect effects such as hypokalaemia. However, deaths from arrhythmias have not been widely reported among home nebuliser users. It is suggested that ECG monitoring is a sensible precaution when the first dose of nebulised bronchodilator is given to a patient with known ischaemic heart disease or cardiac arrhythmias. Perhaps the greatest danger is over reliance by patients on home nebulisers rather than the patients on home nebulisers rather than the summoning of medical help in an emergency.
The frequency with which this happens is not known. Other theoretical hazards include the development of tachyphylaxis during prolonged administration, although there is no evidence for this in clinical practice, ${ }^{31}$ and the risk (which largely applies to hospitalised patients with acute COPD) of giving prolonged nebulised treatment driven by pure oxygen to patients who have type II respiratory failure thus worsening carbon dioxide retention. Careful attention to limiting the duration of nebulisation and the use of air driven nebulisers in selected patients should avoid this hazard, which in practice is rarely a significant problem. The life expectancy of patients with severe COPD is mainly determined by the severity of their air flow obstruction. ${ }^{32} \mathrm{~A}$ recent study has shown that the five year survival of patients using nebulisers and metered dose inhalers was similar. ${ }^{33}$ These patients had similar FEV values on entry to the study $(0.88 \mathrm{l})$ and the five year mortality was approximately $46 \%$, most deaths being due to respiratory failure or lung cancer with the risk of death being directly related to the patient's initial $\mathrm{FEV}_{1}$. These data provide some reassurance as they suggest that the excess mortality amongst nebuliser users in cross sectional studies is probably due to disease severity rather than the treatment.

If ipratropium bromide is used, patients with prostatism should use the smallest possible dose to reduce the ris and patients with a history of glaucoma should use a mouthpiece rather than a face mask. If a face mask must be used every care should be taken to keep the droplets of medication away from the eyes. For example, the mask should be closely fitted to the nose and side vent holes should be taped over using adhesive tape.

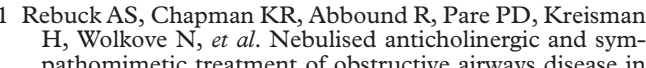
pathomimetic treatment of obstructive airways disease in
the emergency room. Am $\mathcal{Y}$ Med 1987;82:59-64. O'Driscoll BR, Taylor RJ, Horsley MG, Chambers DK, Bernstein A. Nebulised salbutamol with and without ipratropium bromide in acute airflow obstruction. Lance Morley TF, Marozsam E, Zapposodi SJ, Gordon R, Griesback R, Giudice JC. Comparison of beta-adrenergic gents deliverd by nebuliser vs metered dose inhaler with

Moss K, McDonald A, Ferrara L, Myles D, Brischetto M. tetered dose inhaler vs compressor driven nebuliser in the delivery of metaproterenol. Chest 1985;88:53s. response study comparing terbutaline pressurised aeroso administered via a pear sheaped spacer and terbutaline in 6 Turner JR, Corkery KJ, Eckman DE, Gelb AM, Lipavsky A, Sheppard D. Equivalence of continuous flow nebulise and metered dose inhaler with reservoir bag for treatmert Berenberg MJ, Baigelman W, Cupples LA, Pearce L Co parison of metered dose inhaler attached to Aerochamber with updraft nebuliser for administration of meta$87-92$

8 Jasper AC, Mohsenifar Z, Kahan S, Goldberg HS, Koerner SK. Cost benefit comparison of aerosol bronchodilator delivery

9 Mestitz H, Copland JM, App B, McDonald CF. Comparison of outpatient nebulised vs metered dose inhaler terbutaline 

10 Gross, NJ, Petty TL, Friedman M, Skorodin MS, Silvers
GW, Donoghue JF. Dose response to ipratroprium as a nebulised solution in patients with chronic obstructive
pulmonary disease. Am Rev Respir Dis 1989;139:1188-91. 1 O'Driscoll BR, Cochrane GM. Emergency use of nebulised 42:491-3. 2 Tonnesen, F, Laursen LC, Evald T, Stahl E, Ibsen TB.
Bronchodilating effect of terbutaline powder in acute Bronchodilating effect of terbutaline powder in acute
severe bronchial obstruction. Chest 1994;105:697.

13 Hansen NCG. Terbutaline as powder inhalation from bricanyl turbuhaler compared to terbutaline as nebuliser
solution in severe chronic airways obstruction. Eur Respir solution in severe chronic airways obstruction. Eur Resp
f 1989;2:716-20.

14 Sutton PP, Gemmell HG, Innes N, Davidson J, Smith FW, Legge JS, et al. Use of nebulised saline and nebulised
terbutaline as an adjunct to chest physiotherapy. Thorax 1988;43:57-60.
Moayyedi P, Congleton J, Page RL, Pearson SB, Muers
MF. Comparison of nebulised salbutamol and ipratropium bromide with salbutamol alone in the treatment of chronic
obstructive pulmonary disease. Thorax 1995;50:834-7.

obstructive pulmonary disease. Thorax 1995;50:834-7.
16 Brown IG, Chan CS, Kelly CA, Dent AGM Zimmerman BV. Assessment of the clinical usefulness of nebulised
ipratropium bromide in patients with chronic airflow lim-
itation. Thorax 1984;39:272-6. 17 Gross NJ, Skorodin MS. Anticholinergic, antimuscarinic Gross NJ, Skorodin MS. Anticholinergic, antimuscarinic
bronchodilators. Am Rev Respir Dis 1984;129:856-70. 18 O'Driscoll BR, Kay EA, Taylor RJ, Weatherby H, Chetty
MCP, Bernstein A. A long-term prospective assessment
of home nebuliser treatment. Respir Med 1992;86:317-25.
19 O'Driscoll BR. Home nebulised therapy - is it effective? Respir Med 1991;85:1-3.
Newhouse $M$. Aerosol therapy: nebuliser vs

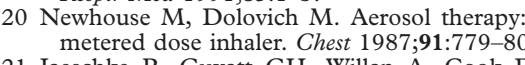

21 Jaeschke R, Guyatt GH, Willan A, Cook D, Harper S, on spirometric parameters, exercise capacity and quality of life in patients with chronic airflow limitation. Thorax 1994;49:479-84. butamol solution in severe chronic airway obstruction. Morrison JFJ, Jones PC, Muers MF. Assessing physiological benefit from domiciliary nebulised bronchodilators in
severe airflow limitation. Eur Respir 7 1992;5:424-9. severe airflow limitation. Eur Respir $\mathcal{F} 1992 ; 5: 424-9$.
Gunawardena KA, Smith AP. Shankelman J. A comparison
of metered dose inhalers with nebulisers for the delivery
of ipratropium bromide in domiciliary practice. Br $\mathcal{F}$ Dis of ipratropium bromide in domiciliary practice. $B r f$ Dis
Chest 1986;80:170-8.

25 Jenkins, SC, Heaton RW, Fulton TJ, Moxham J. Comparison of domiciliary nubulised salbutamol and sal-
butamol from a metered dose inhaler in stable chronic airflow limitation. Chest 1987;91:804-7.
O'Driscoll BR, Kay EA, Taylor RJ, Bernstein A. Home
nebulisers: can optimal therapy be predicted by laboratory
studies? Respir of studies? Respir Med 1990;84:471-7.
Goldman JM, Teale C, Muers MF. Simplifying the assessment of patients with chronic airflow limitation for
selding sessment of patients with chronic airflow limitation for
home nebuliser therapy. Respir Med 1992;86:33-8.
Burrows B, Lebowitz MD. The beta agonist dilemma. N 29 Sears MR, Rea HH, Fenwick J, Gillies AJD, Holst PE, O'Donnell TV, et al. Seventy, five deaths in asthmatics prescribed home nebulisers. $B M 71987 ; 294: 477-80$.
Mullen $M L$, Mullen B, Carey M. The association between
bet beta agonist use and death from asthma. $¥ A M A 1993 ;$
$270: 1842-5$ O'Driscoll BR, Taylor RF, Bernstein A. Does the response

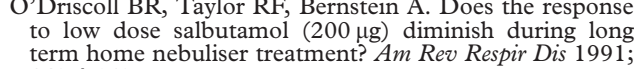
143:A653.
Boushey SF, Thompson HK, North LB, Beale AR, Snow TR. Prognosis in chronic obstructive pulmonary disease. Am Rev Respir Dis 1973;108:1373-83.
3 O'Driscoll BR, Bernstein A. A long term study of symptoms, spirometry and survival amongst home nebuliser users.
Respir Med 1996;90:561-6. 